\title{
Transforming the Energy System with P2P transactions between distributed generators and end consumers
}

\author{
D. Coll-Mayor ${ }^{1}$, A. Notholt ${ }^{1}$ \\ ${ }^{1}$ School of Engineering \\ Reutlingen University \\ Alteburgstr. 15072762 Reutlingen (Germany) \\ Phone/Fax number: +49 (7121) 271-7139, e-mail: Debora.Coll-Mayor@Reutlingen-University.de
}

\begin{abstract}
This paper aims at presenting a solution that enables end customers of the energy system to participate in new local micro-energy-markets by providing them with a distributed, decentralized, transparent and secure Peer

to Peer (P2P) payment system, which functions automatically applying new concepts of Machine to Machine (M2M) communication technologies. This work was performed within the German project VK_2G, funded by the DBU.

The key results were: Providing means to perform microtransactions in a P2P fashion between end consumers and prosumers in local communities at low cost in a transparent and secure manner; Developing a platform with pre-defined smart contracts able to be tailored to different end customers 'needs in an easy way and; Integrating both the market platform as well as the local control of generation and loads. This solution has been developed, integrated and tested in a Laboratory prototype. This paper discusses this solution and presents the results of the first test.
\end{abstract}

Key words. Distributed Generation; Distributed Ledger Technologies; Microgrids

\section{Introduction}

Our society is changing. It is becoming clearer every day that problems such as climate change, limitation of resources or social / economic inequality can no longer be ignored. Unfortunately, all possible solutions to these problems involve drastic changes in our current economic, social and technical structures and processes.

The global energy sector is strongly affected by those problems by having to: drastically reduce the share of fossil fuels ${ }^{1}$; Increment the penetration of renewable energy sources; Increase its efficiency; Adapt to the consequences of the sector coupling and; Face an enormous necessity of growing in developing countries.

${ }^{1}$ In 2018, the German government instructed a commission of experts to analyze from different perspectives the problem of the coal exit. The result of this commission was provided the 31th of January of 2019 recommending the end of the use of coal as fossil fuel at latest the year 2038 [1].
The necessary changes in the energy sector to adapt to this situation require the involvement of the society as a whole.

In Germany, this involvement is already happening and affecting the traditional distribution of roles in the energy economy. The once passive end customer is now assuming responsibilities by becoming a prosumer ${ }^{2}$ or joining energy community models. The municipalities are installing their own distributed generation facilities. The grid operators are being forced to adapt to new smart technologies and processes ${ }^{3}$.

The question here remains on how do we have to adapt our energy system structure in order to enable this to happen in an effective way while ensuring a secure, climate-friendly and competitive energy supply

\section{A. Energy system current structure}

Not many years ago, the energy system was seen as a giant energy lake ("Kupferplatte Model") [3], where large utilities were able to manage and balance inputs and outputs, building up a centralized structure. With the unbundling of activities, these large utilities started to crumble. This fact together with the outburst of renewable energies had as a consequence the opening of the system to many different actors ${ }^{4}$ assuming responsibilities and collaborating in the energy system activities.

Ensuring grid stability in these conditions required clear processes. The once centralized structure was not able to

\footnotetext{
${ }^{2}$ A prosumer is an end customer, which has distributed generation facilities as well as loads and it is able to organize them in an effective way.

${ }^{3}$ For example in the modification of the procedures for further adaptation to electronic market communication required by the digitization law of the energy transition, in the so-called "Marktkommunikation 2020" - "MaKo 2020 "[2]

${ }^{4}$ In Germany we have around 908 Grid operators and 1354 Energy providers [4].
} 
adapt to those new processes, therefore a decentralization of the structure started.

Nowadays, we have part of the processes still based on a centralized structure, for example balancing power in the control area of the transmission grid operator. But we have also processes supporting a partial decentralization, for example in the energy generation. Both structures, centralized and decentralized, are coexisting but it is unclear if they will be able to provide the needed degree of freedom required to adapt to the current changes. A study published in January 2020 affronts this problem by analysing the best mix between central and decentralized elements in a common structure [5], one of the conclusions is that in order to deal with this problem, digitalization of the energy system is unavoidable. Digitalization is key for the future energy system.

\section{Current challenge}

Knowing that digitalization is a key and that we have centralized and decentralized technologies trying to cohabit in a common structure, it is difficult to find the best strategy for matching demand and generation. Therefore, this remains still as a main challenge for our energy system. Even with participation of storage, this does not provide a long term or long capacity solution yet. Since decentralization has been mostly driven by the prosumer role, by installing small generation devices at distribution level, this role must also provide a part of the solution. So, the prosumer or active

involvement of the end customer is centric to solve the problem of matching demand and generation. This involvement must be supported by new business opportunities, which require at the same time new market or grid-supporting processes.

There are many technologies trying to enable an active participation of end-customers and prosumers. For example, demand side management responding to market or grid signals. This kind of solutions are based on centralized or decentralized platforms, which can be market driven or providing services at a fixed price. In the case of a virtual aggregation of those prosumers, endcustomers or distributed resources, this would take the shape of a virtual power plants with decentralized energy management systems. In the case of a real aggregation in a grid knot, this would take the shape of a microgrid. All those kinds of aggregations required a platform, where the decisions are centralized and the conditions for the participation are fixed. Therefore, the freedom of the endcustomers to decide on their own business opportunities is very limited.

Those decentralized platforms limit the freedom of the end customers and at the same time require at least a company which is in charge of it and operates it. This company assumes the middleman role needed to bring together either market or grid operators with prosumers or endcustomers. This increases the costs of the systems, adding a new actor in the energy value chain, as well as the complexity of the solution.
The challenge was here to provide a very simple and low cost system which could increase the freedom of the end customers in implementing their own business ideas and choose their own business partners. In order to reduce costs, the middlemen figure had to be taken out of the energy value chain and the system itself should provide the required transparency and security level. On the other hand, the end-customers could not be performing transactions in a manual way. Therefore, a high level of automation to perform the transactions would be also required. Taking into account those conditions, a solution was proposed.

\section{Proposed Solution}

The solution proposed was a completely automated and customized way to close contracts between different business partners at the end of the energy value chain, by means of smart contracts and distributed ledger technologies. The chosen distributed ledger technology was the Ethereum blockchain, which also provides a good support for smart contracts.

\section{A. Distributed ledger technologies (DLT)}

Distributed ledger technologies offer a means to distribute the book keeping between a community, ensuring transparency and trust between the community members, while taking the middlemen out of the equation. The Ethereum Blockchain ensures transparency by providing a public (between the community) record of all the transactions performed. At the same time, since everything is visible, trust is not needed. Blockchain ensures also security and privacy, making almost impossible for a hacker to use the system for its own benefit.

\section{B. Smart contracts}

The smart contracts offer us the possibility of automating the reactions of the end customers to business opportunities in the system. For example, when a PV System produces energy, this energy will be bought by an end-customer. The added value of the smart contract is to automate the handling conditions (price, quantity...). So, a contract is created based on a set its conditions defined by every business party. Once the contract is uploaded in the Blockchain, it will be activated and the transactions will continuously happen every time the conditions defined in the contract are met. This is a small program activated by an if-question, provoking a reaction in the system, which usually involves a movement of tokens or cryptocurrencies, previously stored in the contract when "signed".

\section{Selection of the Use Case}

The technical solution proposed could be applied to a large range of use cases. In this section, the possible use cases are identified. The German Energy Agency provided in 2019 a study [6] were the main use cases for blockchain in the German energy sector were described. Based on this study and on own research, this paper 
provides the list of the main use cases where the proposed solution would present an added value for the presented challenge:
1) Landlord-to-tenant electricity supply
2) Shared investments in the case of external landlord-to-tenant electricity supply
3) Congestion management in electricity distribution grids (e-mobility)
4) Energy services for buildings \& industrial processes (maintenance)
5) Congestion management in electricity distribution grids (e-mobility)
6) Energy services for buildings \& industrial processes (maintenance)
7) Certificates of origin
8) P2P trading between customers of an electricity supplier

From all those use cases, the Landlord-to-tenant electricity supply use case was selected to be implemented in a laboratory environment. than to the grid. Following the same logic, it would make sense that the tenants would directly pay to the PV system for the energy production rather than to the energy provider, for the energy coming from the grid. In this case, the Blockchain based solution provides a direct means to close a contract between tenants and PV System for the energy which is not going to be fed into the grid. In the case that the production and the consumption happens at the same moment.

This use cases presents a clear advantage: The price of the energy for the end customer will be lower, since there is no need for buying the energy to the energy provider with a fixed and non-negotiable price; The PV System can decide which price is going to sell its production and still be profitable while being cheaper than the grid and; The tenant (end customer) and the PV System can decide their own business conditions without the middlemen being necessary.

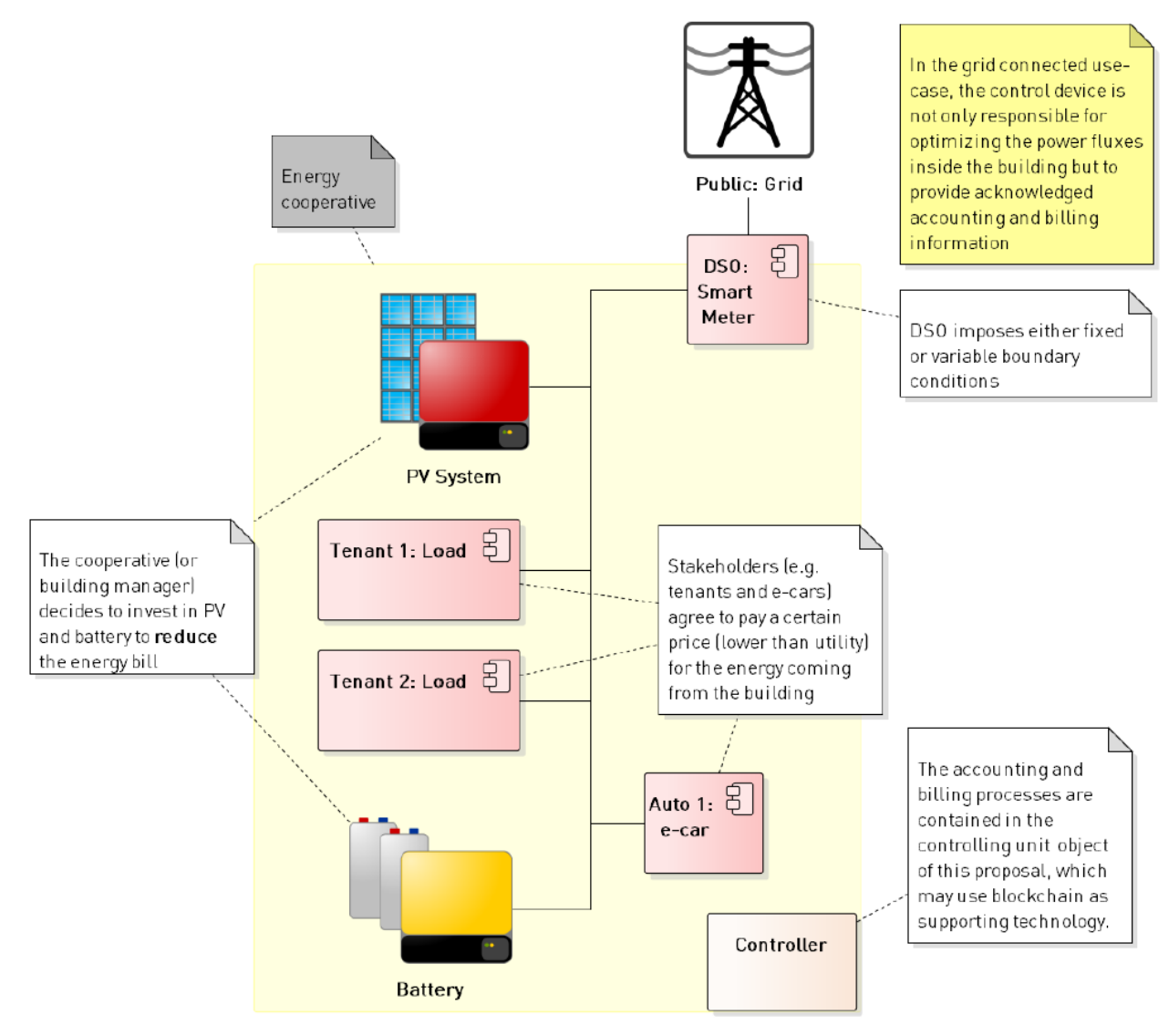

Fig.1. Description of the use case

\section{A. Selected use case:}

Landlord-to-tenant electricity supply

This use case represents a typical situation see on figure 1, where a Landlord has installed a PV system on the roof and there is at least one tenant in the house. Since the PV System is directly on the roof of the house, it makes sense to assume that the feed-in electricity of the PV System will go to the loads of the tenants, if there is demand, rather

\section{Implementation and laboratory test}

The implementation of this use case was done in the laboratory of Control Engineering at the University of Reutlingen. 


\section{A. Laboratory prototype}

The prototype built up for this purpose is shown in figure 2. Every load in the system as well as the grid connection and the PV system were simulated with matlab models and integrated in raspberry pies. The figure represented a house model with different components including e-car, loads, batteries and a shared PV system.

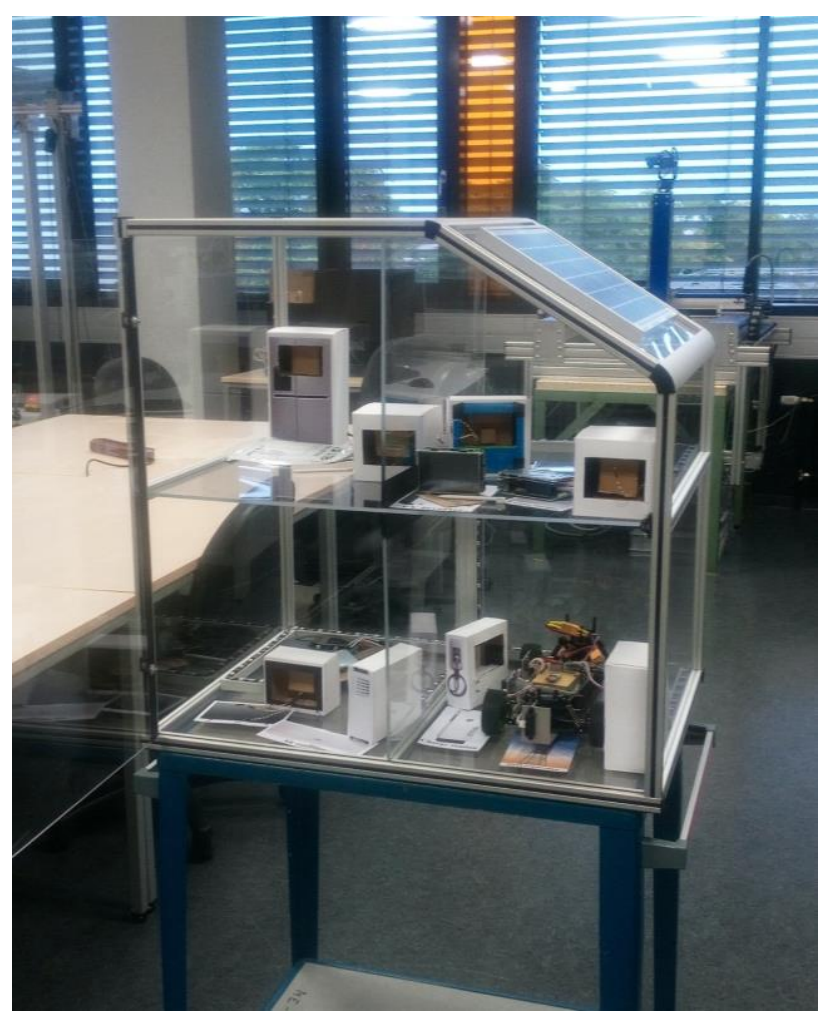

Fig. 2: Laboratory Prototype

\section{B. Blockchain}

The Blockchain defined for this test was a private Blockchain and based on Proof-of-Authority (PoA) consensus mechanism. The Ethereum Virtual Machine (EVM) was used to program and process the smart contracts. and it requires certain fuel to execute them. In the rasperry pies were installed only Light Nodes, due to the lack of capacity for installing full nodes. This only full Node was in the laptop connected to the system which acted as the authority of the system. This laptop represented the landlord. The light nodes represented the tenants.

The Light Nodes were able to make transactions through their public key and their wallet (My Virtual Portmonee) in Meta Mask but could not generate blocks. The nodes were connected through a local RPC network with the host, which was the authority in the system. This was accessed through the port 8042. Also, a file called "staticenodes" was created containing the node information and the RPC information of every node.

The smart contracts were program in solidity (one of the programing languages of the Ethereum Blockchain) and upload to the EVM, to be run when the conditions defined in the test ( $\mathrm{kWh}$ produced and Load connected) were met. See a first smart contract programmed for that purpose on figure 3.

\section{C. $\quad$ Test results}

The test of the system connected to the PoA private blockchain was performed under different conditions: energy prices, production constrains and grid constrains. The blocks were generated every $15 \mathrm{~s}$, simulating a 15 min period. The system was first tested with a Proof-ofWork (PoW) consensus but due to the lack of capacity of the raspberry pies, it didn't work. Therefore, the strategy was changed to the newly developed Ethereum Test Blockchain based on PoA. The results showed the system was stable and the price of the transaction was not heavily influenced by the price of the gas used to perform this transaction. Therefore, the added cost for the end customer participating in the system was almost negligible.

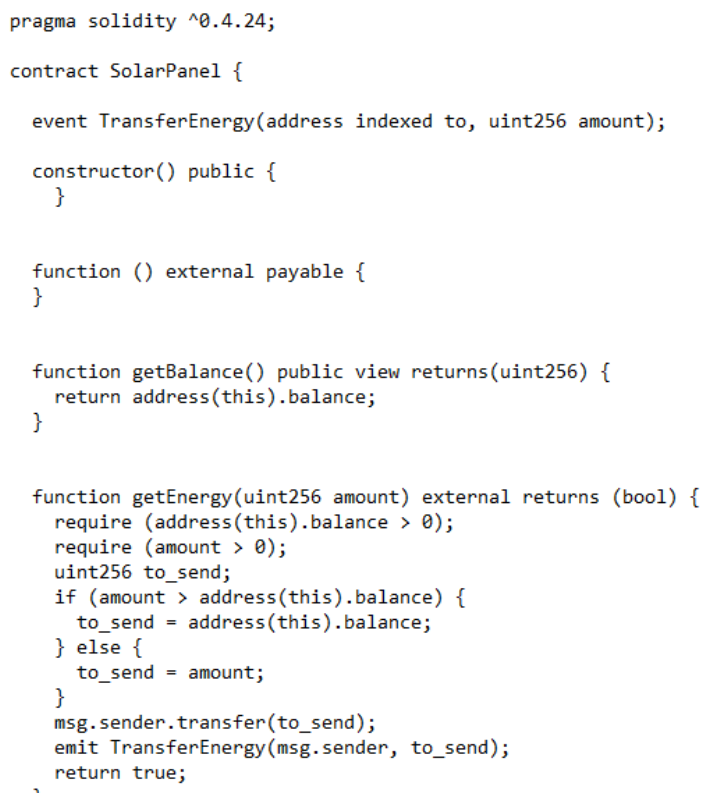

Fig. 3: Smart contract between PV producer and one tenant

\section{Conclusions}

This paper demonstrated the feasibility of the "Landlordto-tenant electricity supply" use case in a laboratory test. The experience showed that the best configuration in order to reduce the resources needed and therefore the running costs of the system was a PoA Blockchain. Since the landlord was the Authority chosen, the system required just raspberry pies and communication to a local network. The trust in the system was granted by the landlord, in the case the landlord would not be a trusted figure, the system should run under a PoW consensus strategy with a consequently increase in the costs of installation and operation.

In order to ensure privacy and enable the PoA, a private blockchain was defined. The main advantage was that all the different nodes were known to the landlord and nobody could connect to the system without a consent of the landlord.

Within the current regulatory framework in Germany, it is now possible to active those kind of business cases involving energy exchange at the end of the energy value chain, within a building between tenants and landlords. 
The idea behind this, is to optimize the energy fluxes in the distribution grid.

\section{Acknowledgements}

This paper presents the first results of the project "Virtuelles Kraftwerk der zweiten Generation" (VK_2G) funded by the DBU (Deutsche Bundesstiftung Umwelt) under number 34798. The authors would like to thank the DBU for its support in the development and implementation of the different use cases, included in the project VK_2G.

\section{References}

[1] Kommission Wachstum, Strukturwandel und Beschäftigung, "Abschlussbericht," Bundesministerium für Wirtschaft und Energie (BMWi), Tech. Rep., 2019.

[2] Beschlusskammer 6, "Festlegung im Verwaltungsverfahren zur weiteren Anpassung der Vorgaben zur elektronischen Marktkommunikation an die Erfordernisse des Gesetzes zur Digitalisierung der Energiewende („Marktkommunikation 2020“ - „MaKo 2020“),” Bundesnetzagentur, Tech. Rep., 2018, accessed 3.2.2020. [Online]. Available: https://www.bundesnetzagentur.de/DE/ServiceFunktionen/Beschlusskammern/BK06/BK6_83_Zug_Mess/ 8351_mako2020/BK6_mako2020_node.html

[3] A. Jahn, "Energiewende und Dezentralität. $\mathrm{Zu}$ den Grundlagen einer politisierten Debatte," Agora Energiewende, Tech. Rep., 2017, accessed 3.2.2020. [Online]. Available: https://www.agoraenergiewende.de/fileadmin2/Projekte/2016/Dezentralitaet/A gora_Dezentralitaet_WEB.pdf

[4] A. Breitkopf. (2020) Anzahl der Unternehmen am Energiemarkt in Deutschland nach Bereichen im Jahr 2019. Statista.com. Accessed 3.2.2020. [Online]. Available: https://de.statista.com/statistik/daten/studie/173884/umfrage /zahl-der-unternehmen-in-den-einzelnen-marktbereichendes-energiemarktes/\#statisticContainer

[5] acatech - Deutsche Akademie der Technikwissenschaften e. V. (Federführung), "Stellungnahme: Zentrale und dezentrale Elemente im Energiesystem Der richtige Mix für eine stabile und nachhaltige Versorgung," Nationale Akademie der Wissenschaften Leopoldina, acatech und Union der deutschen Akademien der Wissenschaften, Berlin, Tech. Rep., 2020.

[6] P. Richard, S. Mamel, and L. Vogel, "dena-multistakeholder studie: Blockchain in der integrierten energiewende," Deutsche Energie-Agentur GmbH (dena), Berlin, Tech. Rep., 2019. [Online]. Available: https://www.dena.de/fileadmin/dena/Publikationen/PDFs/20 19/dena-

Studie_Blockchain_Integrierte_Energiewende_DE4.pdf 